\title{
Application of rhamnolipid biosurfactant produced by Pseudomonas aeruginosa in microbial-enhanced oil recovery (MEOR)
}

\author{
J. M. D. A. Câmara ${ }^{1}$ (D) - M. A. S. B. Sousa ${ }^{1}$ - E. L. Barros Neto ${ }^{1}$ - M. C. A. Oliveira ${ }^{1}$
}

Received: 5 December 2018 / Accepted: 18 February 2019 / Published online: 25 February 2019

(c) The Author(s) 2019

\begin{abstract}
In this study, the biosurfactant produced by Pseudomonas aeruginosa was evaluated in view of its ability to be used in Microbial-Enhanced Oil Recovery (MEOR). This microorganism was isolated from a soil artificially contaminated with crude oil and used to produce rhamnolipid using glycerol as the carbon source. The biosurfactant efficiently reduced water surface tension from 72 to $35.26 \mathrm{mN} / \mathrm{m}$ at its critical micelle concentration of $127 \mathrm{mg} / \mathrm{L}$ and emulsification rate $\left(E_{24}\right)$ of $69 \%$ for the crude oil. Furthermore, it was demonstrated that the rhamnolipid can recover oil, even 2 months after its production, which shows that its biodegradability is not a disadvantage to the application in MEOR. The best result, for a biosurfactant concentration of $100 \%$ above the Critical Micelle Concentration (CMC) and petroleum with API gravity of 21.90, showed that the total recovery factor was $50.45 \pm 0.79 \%$, of which $11.91 \pm 0.39 \%$ corresponds to MEOR.
\end{abstract}

Keywords Pseudomonas aeruginosa $\cdot$ Biosurfactant $\cdot$ Rhamnolipid $\cdot$ Microbial-enhanced oil recovery MEOR

\section{Introduction}

The global energy demand continues to grow and oil remains the main power source, which leads to its use in large proportions (Leder and Shapiro 2008; Najafi-Marghmaleki et al. 2018). However, only a small part of the oil contained in the reservoir is able to be produced by implementation of conventional recovery methods. During primary recovery, which uses the natural energy of the reservoir, it is only possible to produce about 5 to $15 \%$ of the initial amount of hydrocarbon. Posterior to this step, methods such as water or gas injection are used as an attempt to increase the amount of recovered oil, characterizing the secondary recovery (Daghlian Sofla et al. 2016). As a result of the implementation of these operations, still, only $30-50 \%$ of the oil present in the reservoir can be removed (Fernandes et al. 2016), which require the utilization of enhanced oil recovery techniques (EOR) (Sen 2008; Brown 2010; Khajepour et al. 2014). Thus, the demand for more oil to be produced has been pushing for new technologies to be efficiently developed.

J. M. D. A. Câmara

jessicacamara.eq@gmail.com

1 Chemical Engineering Department, Universidade Federal do Rio Grande do Norte, Natal, Brazil
Among the technologies used in EOR, the use of operations to reduce interfacial tension by surfactants is implemented worldwide (Austad and Taugbøl 1995; Al-Wahaibi et al. 2014; Nabipour et al. 2017; Marhaendrajana et al. 2018), because its ability to reduce the interfacial tension between water and oil allows the oil trapped in the pores of the reservoir by capillary forces to be recovered (Van Dyke et al. 1991; Pornsunthorntawee et al. 2008; Li et al. 2012; Guo et al. 2015; Zhang et al. 2015; Kumar and Mandal 2017). However, to achieve a satisfactory result, high concentrations of surfactants are required (Sabatini et al. 2000; Fernandes et al. 2016), which ultimately depends upon high costs for the use of chemical surfactants.

As an alternative, microbial-enhanced oil recovery (MEOR) is being used as a more cost-effective and ecofriendly strategy (Gao and Zekri 2011; Nazar et al. 2011; Pereira et al. 2013; Le et al. 2015; Safdel et al. 2017; Ke et al. 2018). This mechanism uses microorganisms, whether indigenous or exogenous, in the production of metabolites to increase oil recovery (Passman et al. 2013; Armstrong et al. 2015; Le et al. 2015; Jahanbani Veshareh et al. 2018). The metabolites that can be used as surface agents (amphiphilic molecules), biosurfactants, are promising substances in the substitution of chemical surfactants and they can increase the lifespan of mature reservoirs (Sen 2008; Banat et al. 2010; Alvarez et al. 2015). 
Furthermore, the biosurfactants exhibit low toxicity and high biodegradability when compared to synthetic surfactants, making them an environmentally attractive alternative (Rosenberg and Ron 1999; Mohan et al. 2006). However, its biodegradability can be considered a disadvantage, since it can impose strict limits on the time of its surface activity (Passman et al. 2013).

The Rhamnolipid is one of the most investigated biosurfactants employed in enhanced oil recovery (Hörmann et al. 2010; Youssef et al. 2013; Amani 2015; Zhao et al. 2016), due to its promising characteristics as surface agent and its emulsifying properties (Amani et al. 2013; Gudiña et al. 2015; Zhao et al. 2016). It is the most effective biosurfactant regarding to the ability to reduce the water surface tension, as well as the oil-water interfacial tension (Amani and Mehrnia 2010; Hörmann et al. 2010), besides emulsifying the oil and, therefore, increase the trapped oil mobility (Zhao et al. 2016).

Rhamnolipids are mainly produced by Pseudomonas aeruginosa (Hassan et al. 2016) and they have four known homologues, which are formed by one or two rhamnose units linked to one or two chains of fatty acids with eight to fourteen carbon atoms, which can be saturated or not (Hörmann et al. 2010; Müller et al. 2010).

Therefore, the present work evaluated the potential of oil recovery by rhamnolipid produced by a Pseudomonas aeruginosa strain isolated from an artificially contaminated soil. First, the biosurfactant produced was analyzed for its ability to reduce the water surface tension and to emulsify the crude oil, to evaluate its applicability as a surfactant in enhanced oil recovery. In addition, tests with different concentrations of rhamnolipid were carried out to evaluate the effectiveness of the biosurfactant in increasing the enhanced oil recovery (EOR) factor after conventional recovery. Finally, the influence of biodegradability on rhamnolipid ability to increase the amount of recovered oil was evaluated.

\section{Materials and methods}

\section{Bacterial strain}

Sites that are contaminated with oil and/or its derivatives carry a good source of biosurfactant producers, since these pollutants stimulate their metabolism and growth (Alvarez et al. 2015). Thus, for rhamnolipid production, a strain of Pseudomonas aeruginosa was used, which was selected and isolated from a soil artificially contaminated with a solution of crude oil in diesel of $2.50 \mathrm{~g} / \mathrm{L}$ and moistened with the mineral medium described by Robert et al. (1989). The strain was isolated through the qualitative and quantitative media Acetamide Agar and Cetrimide Agar, respectively, which are both selective media for Pseudomonas aeruginosa.

\section{Rhamnolipid production}

Regarding the biosurfactant production, batches were carried out in the shaker at $200 \mathrm{rpm}$, a temperature of $30^{\circ} \mathrm{C}$ for 10 days, and a pH of 7.3. The composition of the medium used for bacteria growth was optimized from previous experiments $\left(125 \mathrm{~g} / \mathrm{L}\right.$ of glycerol, $3.86 \mathrm{~g} / \mathrm{L} \mathrm{NaNO}_{3}, 0.5 \mathrm{~g} / \mathrm{L}$ $\mathrm{MgSO}_{4} .7 \mathrm{H}_{2} \mathrm{O}, 1.0 \mathrm{~g} / \mathrm{L} \mathrm{K}_{2} \mathrm{HPO}_{4}$ and $0.5 \mathrm{~g} / \mathrm{L} \mathrm{KH}_{2} \mathrm{PO}_{4}$ ). Then, the medium was sterilized at $121^{\circ} \mathrm{C}$ and $1.25 \mathrm{~atm}$ for $15 \mathrm{~min}$. As an inoculum, a $2 \%$ by weight peptone nutrient solution was used, which remained in shaker at $200 \mathrm{rpm}$ and $30{ }^{\circ} \mathrm{C}$ for $24 \mathrm{~h}$ (Miguez et al. 2012). After inoculation, the initial concentration of the medium remained at $15 \mathrm{mg} / \mathrm{L}$ of cells. The source of carbon used was glycerol, because it is a low-cost source, since it is a co-product of biodiesel production (De Faria et al. 2011; Sousa et al. 2012).

After the fermentation period, the medium was centrifuged at $3500 \mathrm{rpm}$ for $20 \mathrm{~min}$. While determining the concentration of the crude biosurfactant (cell-free medium), it was subjected to necessary dilutions in distilled water for the oil recovery study.

\section{Biosurfactant chemical analysis}

The measurement of the rhamnolipid concentration was performed by colorimetric quantification in terms of rhamnose (Chandrasekaran and Bemiller 1980). This method consisted in adding $1 \mathrm{~mL}$ of the sample, the cellfree medium, jointly with $4.5 \mathrm{~mL}$ of sulfuric acid solution $(1.6 \mathrm{~kg} / \mathrm{L})$ and incubating for $10 \mathrm{~min}$ at $100{ }^{\circ} \mathrm{C}$. After the solution reached room temperature, $0.1 \mathrm{~mL}$ of thioglycolic acid solution $(5 \mathrm{~g} / \mathrm{L})$ was added, the mixture was homogenized and stored in the absence of light for $3 \mathrm{~h}$. Finally, the reading on the visible UV spectrophotometer was made at $\lambda=400 \mathrm{~nm}$ and $\lambda=430 \mathrm{~nm}$, since the reading at $\lambda=430 \mathrm{~nm}$ indicates the interference of another sugars.

For the characterization of the biosurfactant rhamnolipid, its critical micelle concentration (CMC) and its emulsion index $\left(E_{24}\right)$ for the crude oil were determined.

The produced rhamnolipid was dissolved in distilled water down to various concentrations ranged from 50 to $260 \mathrm{mg} / \mathrm{L}$. For each solution, the surface tension (ST, $\mathrm{mN} / \mathrm{m}$ ) was determined through the Phoenix ${ }^{\circledR}$ tensiometer at $25{ }^{\circ} \mathrm{C}$ by the pendant drop method. The apparatus has a coupled image processing system, which allows the analysis of the curvature profile of each drop to determine the surface tension. In this way, the results were expressed through the mean of ten drops and standard errors were calculated (Song and Springer 1996). For the CMC computation, a curve was used, which relates the surface tensions measured to their mentioned concentrations. 
The same concentration range was used to determine the emulsification index $\left(E_{24}\right)$. The procedure adopted was described by Cooper and Goldenberg (1987) and consisted on, in the case of crude oil, the addition of $2.0 \mathrm{~mL}$ of a hydrocarbon in $2 \mathrm{~mL}$ of crude rhamnolipid extract (cellfree supernatant), followed by vigorous shaking for $2 \mathrm{~min}$ and subsequent incubation at $25^{\circ} \mathrm{C}$ for 24 h. $E_{24}(\%)$ was defined as the percentage of the emulsion column height, as shown in Eq. 1:

$$
E_{24}(\%)=\frac{\text { Emulsion height }}{\text { Total volume height }} \times 100 .
$$

\section{Recovery trials}

\section{Preparation of the sandstone synthetic plug}

The sandstone synthetic plug used in the recovery trials was prepared using sand from the Redinha beach (Natal/ RN, Brazil) and clay from the city of Lagoa dos Velhos/RN, Brazil. To be produced, a composition of $40 \%$ by mass of clay and $60 \%$ by mass of sand was used, setting the granulometry through the sieving in the $(-65+100)$ mesh range. The mixture was hydrated with water, then compacted at $200 \mathrm{kgf} / \mathrm{cm}^{2}$ and, finally, sintered at $850{ }^{\circ} \mathrm{C}$ for $3 \mathrm{~h}$ (Costa et al. 2017).

The porosity of the plug was determined through the capillary rise. In this method, the porous volume is obtained from the mass difference between the dry and wet plug, by approximating its base to a container with water. Then, the porosity value is estimated by dividing the porous volume, which corresponds to the volume of water that the plug absorbed, by the total volume, calculated by the dimensions measured through a pachymeter. The value obtained was $20.49 \pm 0.69 \%$, which is consistent with the porosity of natural sandstones used in advanced recovery studies (Costa et al. 2017).

The permeability value was calculated from the results of an experiment using the fluid injection system (Costa et al. 2017), as shown in Fig. 1. Herewith, the pressure and flow constants obtained along with the water viscosity, the length and the area of the straight section of the sandstone, were applied in Darcy's Law (Eq. 2) to obtain the permeability of each plug:

$k=\frac{-q \mu L}{A \Delta P}$,

where $k$ represents the absolute permeability of the porous medium (mD), $q$ is the rate of fluid flow through the porous medium $\left(\mathrm{cm}^{3} / \mathrm{s}\right), \mu$ is the viscosity of the fluid (cP), $L$ is the length of the porous medium $(\mathrm{cm}), A$ is the cross-sectional area $\left(\mathrm{cm}^{2}\right)$, and $\Delta P$ is the pressure drop (atm).

The permeability of the plugs produced for this work obtained an average value of $36.24 \pm 1.88 \mathrm{mD}$. The deviation presented in this property is due to its sensitivity to the moisture present in the clay.

\section{Brine}

The saline solution used to simulate both the salinity present in a reservoir and the fluid injection in conventional recovery was composed of $2 \%(\mathrm{~m} / \mathrm{v}) \mathrm{KCl}$ and $0.2 \%(\mathrm{~m} / \mathrm{v}) \mathrm{CaCl}_{2}$,

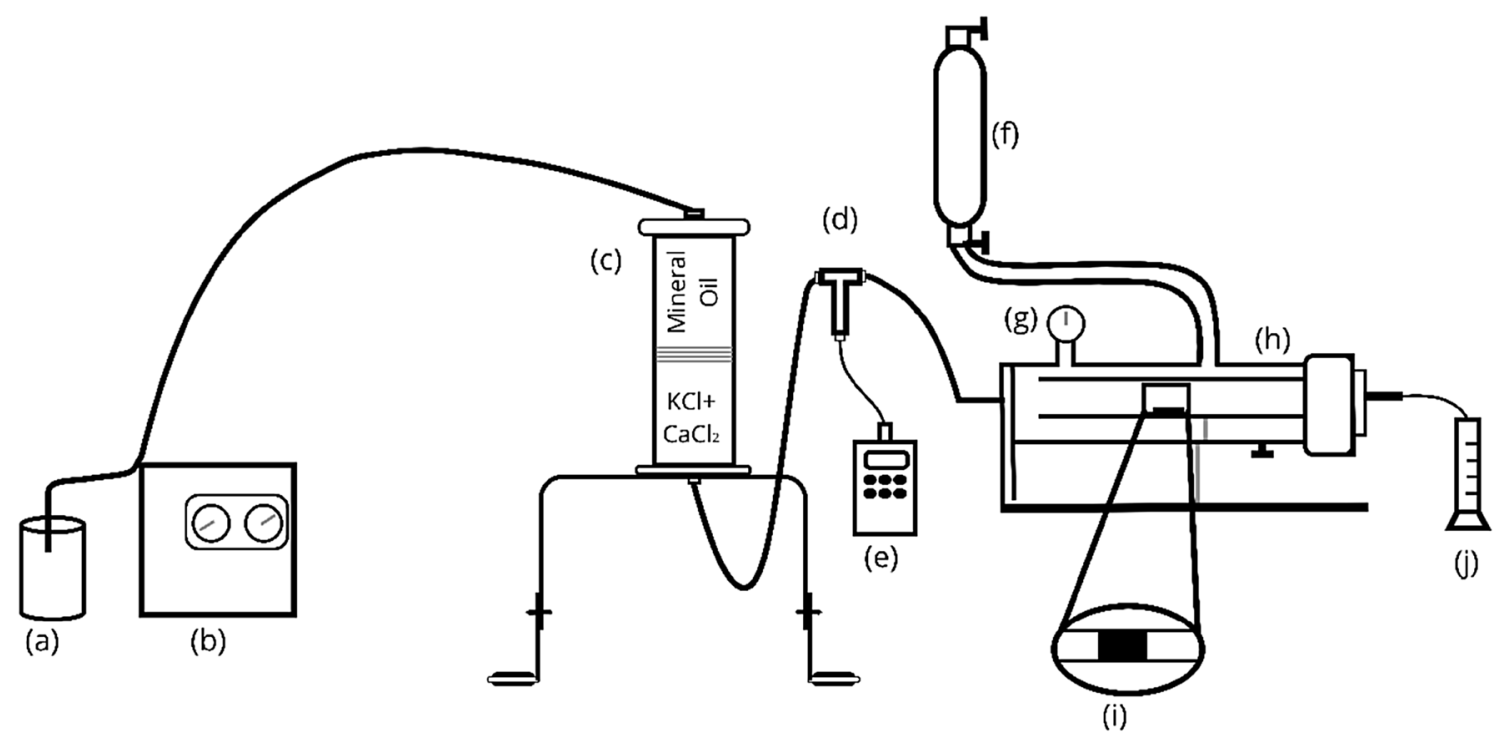

Fig. 1 Fluid injection system: (a) mineral oil reservoir; (b) positive displacement pump; (c) injection cell; (d) and (e) pressure socket and pressure gauge; (f) source of compressed air; (g) holder manometer; (h) holder; (i) plug; (j) test tube 
since they are the most characteristic salts contained in oil reservoirs at the Fazenda Belém Field (CE, Brazil).

\section{Petroleum}

The oil used in the tests was collected from the Fazenda Belém Field (CE, Brazil). However, due to its classification as heavy oil (API gravity of 14), it was necessary to prepare three oil solutions, using S10 diesel as solvent, of 300, 400, and $500 \mathrm{~g} / \mathrm{L}$ to suit the limitations of the experimental apparatus and the indication range of the use of surfactants, as well as to reproduce the viscosity of the petroleum simulating the reservoir conditions which indicate temperatures in the order of $60{ }^{\circ} \mathrm{C}$. These solutions presented an API gravity of $30.34,27.97$, and 21.90. The first two can be classified as medium oils and the last as in the transition between medium and heavy, thus the viscosity of the mixture was adjusted to be properly adequate to the experimental apparatus.

\section{Microbial-enhanced oil recovery (MEOR)}

Recovery assays were performed in the same fluid injection system used to determine the porosity (Fig. 1). The experiment occurred in four stages: saline saturation, oil saturation, conventional recovery, and enhanced recovery. The assays were performed in triplicate.

In the first step (saline saturation), the sandstone plug was saturated with the brine for $100 \mathrm{~min}$ at a flow rate of $1 \mathrm{~mL} /$ min approximately. To do this, the mineral oil contained in the injection cell (c) propelled the saline solution through the holder (h), from the pressure given by the positive displacement pump (b). In the next step, the plug was saturated with the petroleum solution similar to the previous step, only changing the injected fluid. This step also lasted for $100 \mathrm{~min}$ and occurred at a flow rate of $1 \mathrm{~mL} / \mathrm{min}$.

In conventional recovery, the saline solution was again injected to recover the oil. This phase lasted for $85 \mathrm{~min}$ at an approximate flow rate of $0.7 \mathrm{~mL} / \mathrm{min}$ and 20 samples were collected, which were then analyzed for the determination of the amount of oil. The advanced recovery stage differed only in the injected fluid, where $30 \%$ (165 mg/L) and 100\% ( $254 \mathrm{mg} / \mathrm{L})$ above CMC rhamnolipid solution concentrations were used, values defined in previous studies. Higher concentrations may cause the formation of emulsions, which makes difficult to separate oil from water in oil treatment units (Curbelo et al. 2013).

The same procedure was used to evaluate the influence of biodegradability on the rhamnolipid ability to increase the recovered oil factor after conventional enhanced recovery. The biosurfactant at a concentration of $100 \%$ above CMC was incubated at $40{ }^{\circ} \mathrm{C}$ for 2 months. This period was chosen, because it is the average time required to observe the results of the injection of substances in a reservoir (Ke et al. 2018). A $27.97^{\circ} \mathrm{API}$ medium oil was used to the experiment, also performed in triplicate.

\section{Petroleum samples analysis}

The quantification of the recovered oil during the conventional and advanced recovery experiments was performed from the addition of a fixed volume of kerosene to each collected sample, to allow its analysis in the spectrophotometer. The solution was then stirred and centrifuged to admit complete separation of the organic phase. Subsequently, readings were performed on the UV-visible spectrophotometer at $400.1 \mathrm{~nm}$, to enable the calculation of the oil concentration of each sample from the calibration curve previously elaborated in the molecular absorption spectrophotometer 50 Conc Model.

\section{Results}

\section{Critical micellar concentration}

One of the variables able to determine the quality of a surfactant or biosurfactant is its CMC, which is the lowest concentration of surfactant needed to achieve the maximum reduction of surface tension (Ma et al. 2016). In this study, the rhamnolipid produced through Pseudomonas aeruginosa was able to reduce the surface tension of the supernatant to significant values. As shown in Fig. 2, the surface tension decreased from 72 to $35.26 \mathrm{mN} / \mathrm{m}$.

The produced biosurfactant CMC was $127 \mathrm{mg} / \mathrm{L}$, which was obtained from the intersection of the linear adjustment curves of the points before and after the change in the system behavior (Fig. 2). In general, in other studies, the rhamnolipid produced by Pseudomonas aeruginosa strains is able to reduce the surface tension of water from 72 to $30 \mathrm{mN} / \mathrm{m}$ considering a CMC in the ranging from 5 to $200 \mathrm{mg} / \mathrm{L}$

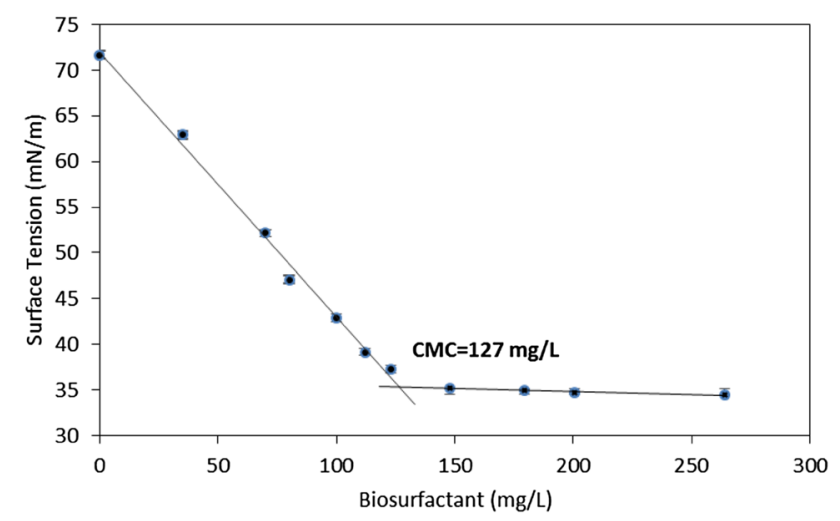

Fig. 2 Determination of the critical micellar concentration 
depending on the components present, since these bacteria are capable of producing four homologs of the compound (Desai and Banat 1997; Hörmann et al. 2010; Müller et al. 2010; Varjani and Upasani 2017).

The temperature rise effect over the CMC up to $100{ }^{\circ} \mathrm{C}$ befalls in conditions that favor micellization, such as the hydration reduction of the hydrophilic group, as shown in other studies. Therefore, since the temperature conditions of the simulated reservoirs are over $60{ }^{\circ} \mathrm{C}$, temperature variations can positively affect the oil recovery, since a higher micellization leads to a greater oil solubilization and facilitates its mobilization (Rosen 2004; Sousa et al. 2014).

\section{Emulsification index}

The emulsification efficiency of the rhamnolipid was evaluated through the computation of the emulsification index $\left(E_{24}\right)$ ranging from 50 to $260 \mathrm{mg} / \mathrm{L}$, at room temperature $\left(30^{\circ} \mathrm{C}\right)$. This procedure was adopted, because the ability to stabilize the emulsion is a function of the biosurfactant concentration (Cooper and Goldenberg 1987; Deepika et al. 2016). Thus, the maximum emulsification index was $69 \%$ for crude oil, as shown in Fig. 3. This result is consistent with other publications, which indicate an emulsion rate of $68 \%$ (Amani et al. 2010) and 85\% (Amani 2015).

This ability allows the formation of oil-water emulsions, assisting the progress of the oil recovery. This is achievable due to the adsorption of the biosurfactant at the interface and consequent reduction of interfacial energy (Darjani et al. 2017).

Therefore, the results attest that the rhamnolipid produced by Pseudomonas aeruginosa strain isolated from an artificially contaminated soil is able to reduce the surface tension of the water and has a good emulsifying capacity. These properties enable the biosurfactant to be an appropriate candidate for MEOR. It can also be observed that the ability to emulsify the oil depends on the surface tension. In Fig. 3, it

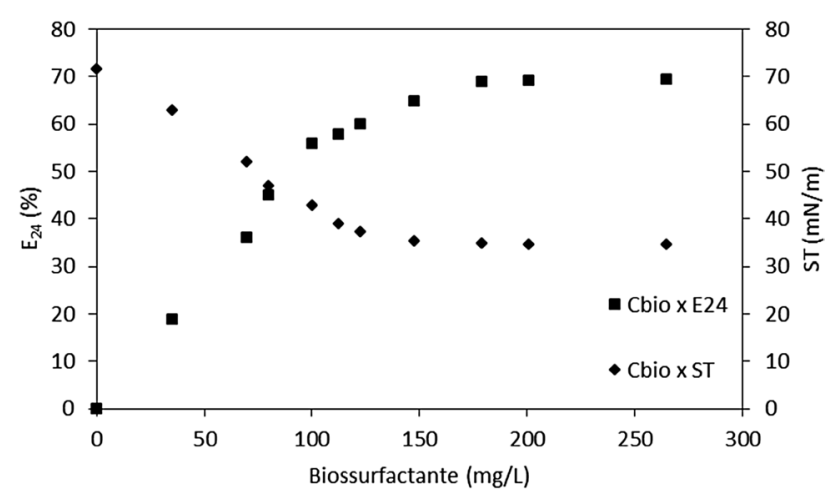

Fig. 3 Emulsification index and surface tension as a function of biosurfactant concentration is possible to verify that from approximately $125 \mathrm{mg} / \mathrm{L}$ the emulsion capacity of the rhamnolipid tends to stabilize and reaches $69 \%$, its highest value, to a concentration in the order of $260 \mathrm{mg} / \mathrm{L}$. This result validates the concentrations to be used in the MEOR assays. By making a linear fit between $E_{24}$ and Surface Tension (ST), Eq. 3 can be obtained, with an $R^{2}=0.993 \mathrm{fit}$, showing that the emulsification rate and surface tension of the aqueous biosurfactant solution have a linear relationship:

$E_{24}=1.8 *(72.2-\mathrm{ST})$.

\section{Microbial-enhanced oil recovery (MEOR)}

The correlation between the recovery factor (\%) as a function of the injected porous volume (a dimensionless parameter) for $30 \%$ biosurfactant concentration above the CMC (i.e., $165 \mathrm{mg} / \mathrm{L}$ ) and $100 \%$ above the $\mathrm{CMC}$ (i.e., $254 \mathrm{mg} / \mathrm{L}$ ) is shown in Figs. 4 and 5, respectively. The recovery factor is the ratio between the volume of recovered oil and the original oil volume, since the injected porous volume is the

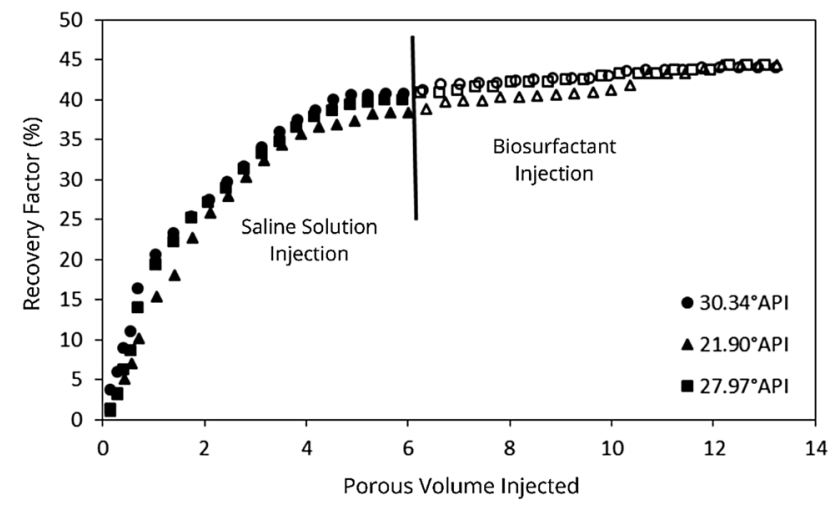

Fig. 4 Recovery factor as a function of porous volume injected for the biosurfactant solution $30 \%$ above CMC

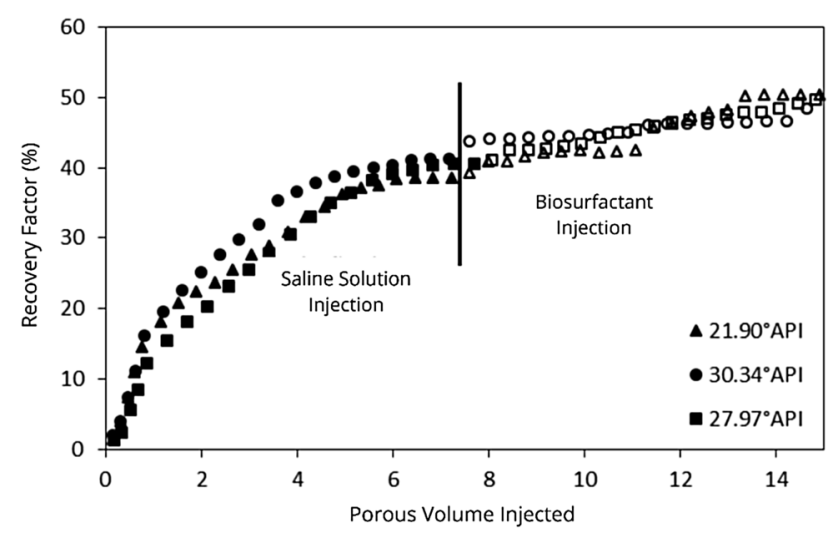

Fig. 5 Recovery factor as a function of porous volume injected for biosurfactant solution $100 \%$ above CMC 
ratio of the volume of injected fluid to the porous volume of the rock. All experiments were carried out at room temperature $\left(30^{\circ} \mathrm{C}\right)$.

As shown in Figs. 4 and 5, with the initial injection of brine, the oil production increases with the increase of the injected porous volume, with stabilization occurring after approximately six porous volumes. It indicates that oil was no longer being recovered. Considering the four situations studied, the recovery factor did not exceed $42 \%$, as shown in Table 1. This result is in agreement with typical oil fields behavior, where $60 \%$ of the original oil remains trapped after conventional recovery (Khaledialidusti et al. 2017; Kumar and Mandal 2017).

The interfacial tension between the oil and the water is reduced due to the injection of the biosurfactant, allowing the trapped oil to be extracted from the pores (Kumar and Mandal 2017). In both cases, for both $30 \%$ and $100 \%$ above CMC, most of the extracted oil is obtained after four porous volumes of rhamnolipid injection. This fact is related to the greater amount of biosurfactant molecules distributed at the oil-water interface.

In general, the results are consistent with the values obtained in the previous studies. In tests performed with the rhamnolipid produced by $P$. aeruginosa SP4, a total recovery factor of $57.01 \pm 0.58 \%$ was obtained using a biosurfactant concentration three times above CMC and in a compacted sand column system (Pornsunthorntawee et al. 2008). For the biosurfactant produced by an Enterobacter cloacae strain and using a micromodel glass system, it was possible to obtain a total recovery factor of $50.5 \%$, being $4.4 \%$ achieved after the injection of the microbial fermentation product (Khajepour et al. 2014). Regarding the biosurfactant produced by Bacillus stearothermophilus SUCPM\#14, it was possible to obtain an increment of $4.21 \%$ after tertiary recovery in samples from southern Iran outcrops (Sarafzadeh et al. 2014). The biosurfactant produced by Bacillus mojavensis (PTCC 1696) was able to obtain a total recovery of $37.46 \%$ of which $6 \%$ corresponds to tertiary recovery in low-permeability dolomite cores (Ghojavand et al. 2012). The partially purified biosurfactant produced by $B$. subtilis RI4914 was able to recover $40 \%$ of oil that remained in sandpacked columns after water flushing (Fernandes et al. 2016).
In addition, it can be observed that, for petroleum with the highest gravity API, a higher recovery factor was obtained during the injection of the saline solution. This can be explained by the fact that, in oils with higher viscosity or lower gravity API, the creation of preferential paths is favored due to the difference in mobility between oil and water (Thomas 2001). The lower recovery factor for oils with lower API grade can also be explained by the formation of asphaltene aggregates and its consequent precipitation (Mozaffari et al. 2015). This can lead to channel blocking and fluid flow limitation (Mozaffari et al. 2017). In addition, these asphaltene arrangements can be adsorbed at the water-oil interface, causing different interface behaviors, which increase interfacial tension and make oil recovery difficult (Liu et al. 2017; Soleymanzadeh et al. 2018).

Injection of rhamnolipid at a concentration of $100 \%$ above CMC practically doubles the recovery factor, when compared to a concentration of $30 \%$ above CMC, for all the studied oils. This fact is due to the higher amount of biosurfactant molecules present in the medium for the same injected porous volume.

The experiment conducted after 2 months of rhamnolipid production obtained a total recovery factor of $49.21 \pm 0.39 \%$, of which $9.25 \pm 0.27 \%$ corresponds to the advanced recovery improved by microorganism. This result can be observed in Fig. 6.

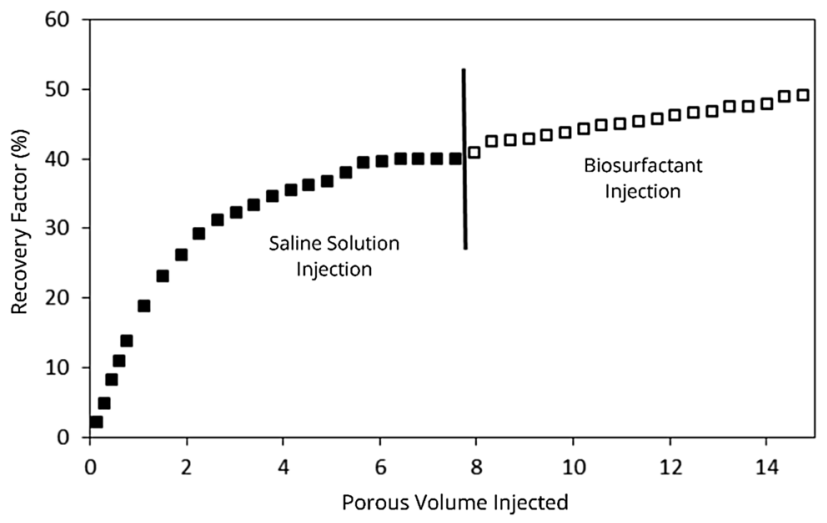

Fig. 6 Recovery factor as a function of porous volume injected for biosurfactant solution $100 \%$ above CMC after 2 months of production
Table 1 Resume of the recovery factors for the MEOR trials

\begin{tabular}{lcccc}
\hline Rhamnolipid concentration & Petroleum & $\begin{array}{l}\text { Conventional recov- } \\
\text { ery factor }(\%)\end{array}$ & $\begin{array}{l}\text { Advanced recov- } \\
\text { ery factor (\%) }\end{array}$ & $\begin{array}{l}\text { Total recov- } \\
\text { ery factor (\%) }\end{array}$ \\
\hline $30 \%$ above CMC & $21.90^{\circ}$ API & $38.44 \pm 1.61$ & $5.92 \pm 0.32$ & $44.37 \pm 1.67$ \\
& $27.97^{\circ}$ API & $40.01 \pm 1.30$ & $4.39 \pm 0.28$ & $44.40 \pm 1.03$ \\
$100 \%$ above CMC & $30.34^{\circ}$ API & $40.81 \pm 0.84$ & $3.25 \pm 0.26$ & $44.06 \pm 0.66$ \\
& $21.90^{\circ}$ API & $38.54 \pm 0.87$ & $11.91 \pm 0.39$ & $50.45 \pm 0.79$ \\
& $27.97^{\circ}$ API & $40.53 \pm 0.63$ & $9.10 \pm 0.39$ & $49.63 \pm 0.88$ \\
& $30.34^{\circ}$ API & $41.18 \pm 0.92$ & $7.40 \pm 0.48$ & $48.58 \pm 0.44$ \\
\hline
\end{tabular}


Through a hypothesis test, with a significance level of 0.05 and assuming the normality of the data, it was observed that the value obtained after 2 months has a probability of $96.6 \%$ being equal to the first result. This demonstrates that the biodegradability of the bisurfactant is not a disadvantage for its application in MEOR.

This way, the rhamnolipid biosurfactant proved to be effective in increasing the recovered oil factor after the injection of brine (conventional recovery). Improved results are obtained when higher concentrations of biosurfactant are used. At first, the use of higher concentrations of surfactant may lead to low economic profitability, but the use of lowcost raw materials as a source of carbon for their production, such as glycerol, may reduce costs (De Faria et al. 2011; Sousa et al. 2012).

\section{Conclusion}

In this study, a strain of Pseudomonas aeruginosa isolated from a soil that was artificially contaminated by petroleum was able to produce a rhamnolipid biosurfactant with adequate characteristics to be used in the advanced recovery of petroleum. The surfactant produced was able to reduce the surface tension of the water to $35.26 \mathrm{mN} / \mathrm{m}$ and showed a good capacity of emulsification for the crude oil (emulsion rate of $69 \%$ ). In addition, the ratio of the emulsion rate and the surface tension was shown.

The ability of biosurfactant to recover oil has also been demonstrated through six trials promoted with two concentrations of rhamnolipid, $30 \%$ and $100 \%$ above CMC, and two types of oil, API gravity of 30.34, 27.97, and 21.90. The best result was a total Recovery Factor of $50.45 \pm 0.79 \%$, of which $11.91 \pm 0.39 \%$ corresponds to the advanced recovery improved by microorganism. This work demonstrates that the rhamnolipid can be efficiently used for MEOR applications, since it presented expressive results when compared with other biosurfactants including synthetic surfactants; in addition, its biodegradability did not prove to be a disadvantage.

Acknowledgements The authors thank the Coordenação de Aperfeiçoamento de Pessoal de Nível Superior (CAPES) for the financial supports.

Open Access This article is distributed under the terms of the Creative Commons Attribution 4.0 International License (http://creativeco mmons.org/licenses/by/4.0/), which permits unrestricted use, distribution, and reproduction in any medium, provided you give appropriate credit to the original author(s) and the source, provide a link to the Creative Commons license, and indicate if changes were made.

\section{References}

Alvarez V, Jurelevicius D, Marques J et al (2015) Bacillus amyloliquefaciens TSBSO 3.8, a biosurfactant-producing strain with biotechnological potential for microbial enhanced oil recovery. Colloids Surf B Biointerfaces 136:14-21. https://doi.org/10.1016/j.colsu rfb.2015.08.046

Al-Wahaibi Y, Joshi S, Al-Bahry S et al (2014) Biosurfactant production by Bacillus subtilis B30 and its application in enhancing oil recovery. Colloids Surf B Biointerfaces 114:324-333. https://doi. org/10.1016/j.colsurfb.2013.09.022

Amani H (2015) Study of enhanced oil recovery by rhamnolipids in a homogeneous 2D micromodel. J Pet Sci Eng 128:212-219. https ://doi.org/10.1016/j.petrol.2015.02.030

Amani H, Mehrnia MR (2010) Scale up and application of biosurfactant from Bacillus subtilis in enhanced oil recovery. Appl Biochem Biotechnol 162:510-523. https://doi.org/10.1007/s1201 0-009-8889-0

Amani H, Sarrafzadeh MH, Haghighi M, Mehrnia MR (2010) Comparative study of biosurfactant producing bacteria in MEOR applications. J Pet Sci Eng 75:209-214. https://doi.org/10.1016/j.petro 1.2010.11.008

Amani H, Müller MM, Syldatk C, Hausmann R (2013) Production of microbial rhamnolipid by Pseudomonas aeruginosa MM1011 for ex situ enhanced oil recovery. Appl Biochem Biotechnol 170:1080-1093. https://doi.org/10.1007/s12010-013-0249-4

Armstrong RT, Wildenschild D, Bay BK (2015) The effect of pore morphology on microbial enhanced oil recovery. J Pet Sci Eng 130:16-25. https://doi.org/10.1016/j.petrol.2015.03.010

Austad T, Taugbøl K (1995) Chemical flooding of oil reservoirs 1. Low tension polymer flood using a polymer gradient in the three-phase region. Colloids Surf A Physicochem Eng Asp 101:87-97. https ://doi.org/10.1016/0927-7757(95)03231-2

Banat IM, Franzetti A, Gandolfi I et al (2010) Microbial biosurfactants production, applications and future potential. Appl Microbiol Biotechnol 87:427-444. https://doi.org/10.1007/s00253-010-2589-0

Brown LR (2010) Microbial enhanced oil recovery (MEOR). Curr Opin Microbiol 13:316-320. https://doi.org/10.1016/J. MIB.2010.01.011

Chandrasekaran EV, Bemiller J (1980) Constituent analysis of glycosaminoglycans. In: Methods in carbohydrate chemistry. Academic Press, New York, pp 89-96

Cooper DG, Goldenberg BG (1987) Surface-active agents from two Bacillus species. Appl Envir Microbiol 53:224-229

Costa SED, Barros Neto EL, Oliveira MCA, Santos JSC (2017) Mechanical and petrophysical analysis of synthetic sandstone for enhanced oil recovery applications. Braz J Pet Gas 11:131-140. https://doi.org/10.5419/bjpg2017-0011

Curbelo FDS, Garnica AIC, Neto ELB (2013) Enhanced oil recovery and adsorption of ionic surfactant. Pet Sci Technol 31:663-671. https://doi.org/10.1080/10916466.2010.523750

Daghlian Sofla SJ, Sharifi M, Hemmati Sarapardeh A (2016) Toward mechanistic understanding of natural surfactant flooding in enhanced oil recovery processes: the role of salinity, surfactant concentration and rock type. J Mol Liq 222:632-639. https://doi. org/10.1016/j.molliq.2016.07.086

Darjani S, Koplik J, Pauchard V (2017) Extracting the equation of state of lattice gases from random sequential adsorption simulations by means of the Gibbs adsorption isotherm. Phys Rev E. https://doi. org/10.1103/PhysRevE.96.052803

De Faria AF, Teodoro-Martinez DS, De Oliveira Barbosa GN et al (2011) Production and structural characterization of surfactin (C 14/Leu7) produced by Bacillus subtilis isolate LSFM-05 grown on raw glycerol from the biodiesel industry. Process Biochem 46:1951-1957. https://doi.org/10.1016/j.procbio.2011.07.001

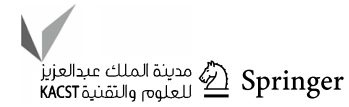


Deepika KV, Kalam S, Ramu Sridhar P et al (2016) Optimization of rhamnolipid biosurfactant production by mangrove sediment bacterium Pseudomonas aeruginosa KVD-HR42 using response surface methodology. Biocatal Agric Biotechnol 5:38-47. https ://doi.org/10.1016/j.bcab.2015.11.006

Desai JD, Banat IM (1997) Microbial production of surfactants and their commercial potential. Microbiol Mol Biol Rev 61:47-64. https://doi.org/10.1016/S0140-6701(97)84559-6

Fernandes PL, Rodrigues EM, Paiva FR et al (2016) Biosurfactant, solvents and polymer production by Bacillus subtilis RI4914 and their application for enhanced oil recovery. Fuel 180:551-557. https://doi.org/10.1016/j.fuel.2016.04.080

Gao CH, Zekri A (2011) Applications of microbial-enhanced oil recovery technology in the past decade. Energy Sources Part A Recover Util Environ Eff 33:972-989. https://doi.org/10.1080/1556703090 3330793

Ghojavand H, Vahabzadeh F, Shahraki AK (2012) Enhanced oil recovery from low permeability dolomite cores using biosurfactant produced by a Bacillus mojavensis (PTCC 1696) isolated from Masjed-I Soleyman field. J Pet Sci Eng 81:24-30. https://doi. org/10.1016/j.petrol.2011.12.002

Gudiña EJ, Rodrigues AI, Alves E et al (2015) Bioconversion of agroindustrial by-products in rhamnolipids toward applications in enhanced oil recovery and bioremediation. Bioresour Technol 177:87-93. https://doi.org/10.1016/j.biortech.2014.11.069

Guo S, Wang H, Shi J et al (2015) Synthesis and properties of a novel alkyl-hydroxyl-sulfobetaine zwitterionic surfactant for enhanced oil recovery. J Pet Explor Prod Technol 5:321-326. https://doi. org/10.1007/s13202-014-0141-y

Hassan M, Essam T, Yassin AS, Salama A (2016) Optimization of rhamnolipid production by biodegrading bacterial isolates using Plackett-Burman design. Int J Biol Macromol 82:573-579. https ://doi.org/10.1016/j.ijbiomac.2015.09.057

Hörmann B, Müller MM, Syldatk C, Hausmann R (2010) Rhamnolipid production by Burkholderia plantarii DSM 9509T. Eur J Lipid Sci Technol 112:674-680. https://doi.org/10.1002/ejlt.201000030

Jahanbani Veshareh M, Ganji Azad E, Deihimi T et al (2018) Isolation and screening of Bacillus subtilis MJ01 for MEOR application: biosurfactant characterization, production optimization and wetting effect on carbonate surfaces. J Pet Explor Prod Technol. https ://doi.org/10.1007/s13202-018-0457-0

Ke CY, Lu GM, Li Y, Bin et al (2018) A pilot study on large-scale microbial enhanced oil recovery (MEOR) in Baolige Oilfield. Int Biodeterior Biodegrad 127:247-253. https://doi.org/10.1016/j. ibiod.2017.12.009

Khajepour H, Mahmoodi M, Biria D, Ayatollahi S (2014) Investigation of wettability alteration through relative permeability measurement during MEOR process: amicromodel study. J Pet Sci Eng 120:10-17. https://doi.org/10.1016/j.petrol.2014.05.022

Khaledialidusti R, Kleppe J, Enayatpour S (2017) Evaluation of surfactant flooding using interwell tracer analysis. J Pet Explor Prod Technol 7:853-872. https://doi.org/10.1007/s13202-016-0288-9

Kumar A, Mandal A (2017) Synthesis and physiochemical characterization of zwitterionic surfactant for application in enhanced oil recovery. J Mol Liq 243:61-71. https://doi.org/10.1016/j.molli q.2017.08.032

Le JJ, Wu XL, Wang R et al (2015) Progress in pilot testing of microbial-enhanced oil recovery in the Daqing oilfield of North China. Int Biodeterior Biodegrad 97:188-194. https://doi.org/10.1016/j. ibiod.2014.10.014

Leder F, Shapiro JN (2008) This time it's different. An inevitable decline in world petroleum production will keep oil product prices high, causing military conflicts and shifting wealth and power from democracies to authoritarian regimes. Energy Policy 36:2840-2842. https://doi.org/10.1016/j.enpol.2008.04.015
Li N, Zhang G, Ge J et al (2012) Ultra-low interfacial tension between heavy oil and betaine-type amphoteric surfactants. J Dispers Sci Technol 33:258-264. https://doi.org/10.1080/01932 691.2011.561177

Liu F, Darjani S, Akhmetkhanova N et al (2017) Mixture effect on the dilatation rheology of Asphaltenes-Laden interfaces. Langmuir 33:1927-1942. https://doi.org/10.1021/acs.langmuir.6b03958

Ma KY, Sun MY, Dong W et al (2016) Effects of nutrition optimization strategy on rhamnolipid production in a Pseudomonas aeruginosa strain DN1 for bioremediation of crude oil. Biocatal Agric Biotechnol 6:144-151. https://doi.org/10.1016/j.bcab.2016.03.008

Marhaendrajana T, Kurnia R, Irfana D et al (2018) Study to improve an amphoteric sulfonate alkyl ester surfactant by mixing with nonionic surfactant to reduce brine-waxy oil interfacial tension and to increase oil recovery in sandstone reservoir: T-KS field, Indonesia. J Pet Explor Prod Technol. https://doi.org/10.1007/ s13202-018-0503-y

Miguez M, Botelho PN, Azeredo N et al (2012) Selection of yeasts for the production of L-phenyl acetyl carbinol. Chem Eng Trans 27:163-168

Mohan PK, Nakhla G, Yanful EK (2006) Biokinetics of biodegradation of surfactants under aerobic, anoxic and anaerobic conditions. Water Res 40:533-540. https://doi.org/10.1016/j.watre s.2005.11.030

Mozaffari S, Tchoukov P, Atias J et al (2015) Effect of asphaltene aggregation on rheological properties of diluted Athabasca bitumen. Energy Fuels 29:5595-5599. https://doi.org/10.1021/acs. energyfuels.5b00918

Mozaffari S, Tchoukov P, Mozaffari A et al (2017) Capillary driven flow in nanochannels - application to heavy oil rheology studies. Colloids Surf A Physicochem Eng Asp 513:178-187. https://doi. org/10.1016/j.colsurfa.2016.10.038

Müller MM, Hörmann B, Syldatk C, Hausmann R (2010) Pseudomonas aeruginosa PAO1 as a model for rhamnolipid production in bioreactor systems. Appl Microbiol Biotechnol 87:167-174. https:// doi.org/10.1007/s00253-010-2513-7

Nabipour M, Ayatollahi S, Keshavarz P (2017) Application of different novel and newly designed commercial ionic liquids and surfactants for more oil recovery from an Iranian oil field. J Mol Liq 230:579-588. https://doi.org/10.1016/j.molliq.2017.01.062

Najafi-Marghmaleki A, Kord S, Hashemi A, Motamedi H (2018) Experimental investigation of efficiency of MEOR process in a carbonate oil reservoir using Alcaligenes faecalis: impact of interfacial tension reduction and wettability alteration mechanisms. Fuel 232:27-35. https://doi.org/10.1016/j.fuel.2018.05.117

Nazar MF, Shah SS, Khosa MA (2011) Microemulsions in enhanced oil recovery: a review. Pet Sci Technol 29:1353-1365. https://doi. org/10.1080/10916460903502514

Passman FJ, Skovhus TL, Whitby C et al (2013) Prospects for using native and recombinant rhamnolipid producers for microbially enhanced oil recovery. Int Biodeterior Biodegradation 81:133-140

Pereira JFB, Gudiña EJ, Costa R et al (2013) Optimization and characterization of biosurfactant production by Bacillus subtilis isolates towards microbial enhanced oil recovery applications. Fuel 111:259-268. https://doi.org/10.1016/j.fuel.2013.04.040

Pornsunthorntawee O, Arttaweeporn N, Paisanjit S et al (2008) Isolation and comparison of biosurfactants produced by Bacillus subtilis PT2 and Pseudomonas aeruginosa SP4 for microbial surfactant-enhanced oil recovery. Biochem Eng J 42:172-179. https://doi.org/10.1016/j.bej.2008.06.016

Robert M, Mercade ME, Bosch MP et al (1989) Effect of the carbon source on biosurfactant production by Pseudomonas aeruginosa 44T1. Biotechnol Lett 11:871-874

Rosen MJ (2004) Surfactants and interfacial phenomena, 3rd edn. Wiley, New Jersey 
Rosenberg E, Ron EZ (1999) High- and low-molecular-mass microbial surfactants. Appl Microbiol Biotechnol 52:154-162. https://doi. org/10.1007/s002530051502

Sabatini DA, Knox RC, Harwell JH, Wu B (2000) Integrated design of surfactant enhanced DNAPL remediation: efficient supersolubilization and gradient systems. J Contam Hydrol 45:99-121. https:// doi.org/10.1016/S0169-7722(00)00121-2

Safdel M, Anbaz MA, Daryasafar A, Jamialahmadi M (2017) Microbial enhanced oil recovery, a critical review on worldwide implemented field trials in different countries. Renew Sustain Energy Rev 74:159-172. https://doi.org/10.1016/j.rser.2017.02.045

Sarafzadeh P, Niazi A, Oboodi V et al (2014) Investigating the efficiency of MEOR processes using Enterobacter cloacae and Bacillus stearothermophilus SUCPM\#14 (biosurfactant-producing strains) in carbonated reservoirs. J Pet Sci Eng 113:46-53. https ://doi.org/10.1016/j.petrol.2013.11.029

Sen R (2008) Biotechnology in petroleum recovery: the microbial EOR. Prog Energy Combust Sci 34:714-724. https://doi. org/10.1016/j.pecs.2008.05.001

Soleymanzadeh A, Yousefi M, Kord S, Mohammadzadeh O (2018) A review on methods of determining onset of asphaltene precipitation. J Pet Explor Prod Technol 1-22. https://doi.org/10.1007/ s00125-013-2929-6

Song B, Springer J (1996) Determination of interfacial tension from the profile of a pedant drop using computer-aided image processing- theoretical. J Colloid Interface Sci 184:64-76

Sousa M, Melo VMM, Rodrigues S et al (2012) Screening of biosurfactant-producing Bacillus strains using glycerol from the biodiesel synthesis as main carbon source. Bioprocess Biosyst Eng 35:897-906. https://doi.org/10.1007/s00449-011-0674-0
Sousa JR, Correia JAC, Melo VMM et al (2014) Cinética e caracterização de ramnolipídeos produzidos por pseudomonas aeruginosa msic02 utilizando glicerol como fonte de carbono. Quim Nova 37:431-441. https://doi.org/10.5935/0100-4042.20140064

Thomas JE (org. (2001) Fundamentos da engenharia de petróleo. Editora Interciência, Rio de Janeiro

Van Dyke MI, Lee H, Trevors JT (1991) Applications of microbial surfactants. Biotechnol Adv 9:241-252. https://doi. org/10.1016/0734-9750(91)90006-H

Varjani SJ, Upasani VN (2017) Critical review on biosurfactant analysis, purification and characterization using rhamnolipid as a model biosurfactant. Bioresour Technol 232:389-397. https:// doi.org/10.1016/j.biortech.2017.02.047

Youssef N, Simpson DR, McInerney MJ, Duncan KE (2013) In-situ lipopeptide biosurfactant production by Bacillus strains correlates with improved oil recovery in two oil wells approaching their economic limit of production. Int Biodeterior Biodegrad 81:127-132. https://doi.org/10.1016/j.ibiod.2012.05.010

Zhang QQ, Cai BX, Xu WJ et al (2015) Novel zwitterionic surfactant derived from castor oil and its performance evaluation for oil recovery. Colloids Surf A Physicochem Eng Asp 483:87-95. https ://doi.org/10.1016/j.colsurfa.2015.05.060

Zhao F, Zhou JD, Ma F et al (2016) Simultaneous inhibition of sulfatereducing bacteria, removal of $\mathrm{H} 2 \mathrm{~S}$ and production of rhamnolipid by recombinant Pseudomonas stutzeri Rhl: applications for microbial enhanced oil recovery. Bioresour Technol 207:24-30. https:// doi.org/10.1016/j.biortech.2016.01.126 